\title{
United Nations World Tourism Organization Study on Online Guest Reviews and Hotel Classification Systems: An Integrated Approach
}

\author{
United Nations World Tourism Organization (UNWTO) ${ }^{1}$ \\ Anita Blomberg-Nygard ${ }^{2}$ \\ Chris K. Anderson ${ }^{3}$
}

October 27, 2015

Final version published in Service Science 8(2), 139-151

1. UNWTO, Madrid 28020, Spain

2. Anita Blomberg-Nygard, Norwegian Accreditation, Lillestrøm bedriftssenter, N-2001

Lillestrøm, Norway, abn@akkreditert.no

3. Chris K. Anderson, Cornell University, Ithaca, New York 14853, cka9@cornell.edu 


\begin{abstract}
The proliferation of online travel-related content is changing how consumers book and research travel. Before making an online hotel reservation, consumers visit on average almost 14 different travel-related sites, with about 3 visits per site, and carry out 9 travel-related searches on search engines. Official hotel classifications are often used by consumers as a filter mechanism in the hotel research and booking process, with guest reviews being used to make a final selection among a smaller group of hotels. As online reviews continue to grow in popularity, questions arise as to whether traditional hotel classifications systems are becoming less relevant. Traditionally, classification systems have been about amenities, whereas guest reviews are about meeting expectations; thus, guest reviews may be able to provide a quality check on the amenities that are required as part of the classification system. We outline an integrated approach for the inclusion of online reviews into hotel classification whereby guest reviews add a quality dimension to hotel classifications, thereby refining the classification.
\end{abstract}

Keywords: online reputation; product classification; hotels 
UNWTO 3

\section{United Nations World Tourism Organization Study on Online Guest Reviews and Hotel Classification Systems: An Integrated Approach}

Tourism is one of the most dynamic economic sectors of our times. Representing $9 \%$ of the world's gross domestic product, 30\% of service exports, and 1 in every 11 jobs, the sector has grown from the privilege of a few to a global socioeconomic activity moving billions of people across borders every year. In just six decades, tourism has seen a dramatic rise in breadth and scope. In 1950, a mere 25 million people traveled the globe, mainly to and from the traditional destinations of Europe and North America. In 2013, the annual number of international tourists hit 1,087 million, with emerging economies increasingly capturing the imagination of travelers. Beyond this exponential growth, the sector has significantly transformed, with few areas showing so much dynamic change and innovation as the online space (UNWTO 2015). The emergence of user-generated content reviews has completely revolutionized the travel decision-making process as increasingly “would-be travelers” depend on online guest reviews to make their purchase decisions. This impact has been especially evident for accommodation providers.

Both guest reviews and hotel classification systems serve important and complementary purposes; whereas hotel classifications concentrate on objective, amenity-based elements, guest review systems lend more focus to the perception of service-related elements. Our research shows that both are necessary, but that both consumers and the industry are interested in seeing a closer fit between the two, as well as a common framework for guest reviews. Moreover, with online activity set to expand, boosted by the growth in travel-specific websites and social media and the widening appeal and availability of mobile technologies, it is imperative that hotel offerings are presented in a way that is consistent with consumer needs. 
The emergence of online guest reviews in the last decade has challenged the necessity for hotel classification systems, with critics arguing that guest reviews are better at providing a benchmark on the quality and range of services a hotel can offer. Conversely, critics of guest review systems point to the difficulty of verifying their authenticity and to their lack of objectivity. Despite these issues, there is the potential for hotel classification systems and guest reviews to play important, and not necessarily mutually exclusive, roles in the establishment of a commonly held understanding of accommodation quality, as the matching of offer and expectation is critical for success. To forward that integration, we highlight the historic use of hotel classification systems and outline recent developments in user reviews. Through the use of secondary data relating user reviews and hotel classifications as well as primary data collected through surveys and questionnaires, we outline a framework for the inclusion of user-generated content into a modified form of hotel classification.

\section{Background}

In the following section, we outline the nature of hotel classification and user reviews as well as present a review of relevant literature dealing with hotel classification and online word of mouth.

\section{Hotel Classification Systems}

Official hotel classification originated in 1905 with the advent of the Automobile Association (AA) in the United Kingdom. The AA included its first listing of hotels in its 1908 handbook and formally introduced the star system of ranking hotels in 1912, but did not introduce its first hotel guidebook until 1967, with its online directory going live in 1996, and its mobile app being launched in 2011. Not much has changed in 100-plus years other than how information is disseminated. Hotel rating systems have received somewhat limited attention from 
researchers. Callan (1990) indicated an increased emphasis on service quality, because ratings should strive to ensure consumer expectations (as communicated through a rating system) are met. But although hotel rating systems have started to emphasize service quality, their measurement is very subjective (Callan 1995). Su and Sun (2007) present a thorough review of several hotel classification systems (United Kingdom, United States, China, and Taiwan) while highlighting Taiwans’ attempts to quantify service quality as part of their hotel rating system. Similarly Fernandez and Bedia (2004) survey hotel guests in northern Spain using a variant of the SERVQUAL instrument (Parasuraman et al. 1985), concluding that although service quality varies within a hotel class (star level), it does not necessarily increase with increasing star level.

Traditional hotel classification relies on the opinions of experts. Hotels are similar to many other goods and services with established expert-based rating agencies such as Consumer Reports or Zagat that evaluate and score products on various performance measures. Third-party product reviews are often viewed as more credible than information produced directly by the company (Zhu and Zhang 2010). However, expert reviews may not be as predictive of sales (Reinstein and Snyder 2005) because experts’ opinions of experiential products may fail to reflect the average consumer's tastes or preferences (Eliashberg and Shugan 1997). This heterogeneity among evaluators may result in uncertainty among buyers, resulting in further information search (Shapiro 1982). O’Connor (2010) compared online reviews with expert feedback, and although he found a strong match between ratings provided by experts with the opinions expressed in online reviews, he did find discrepancies for hotels of higher star levels or classes.

Reviewers of experiential goods may also receive service experiences that are better than those of the average consumer. For example, the New York Times critic or Zagat rater is often 
singled out and provided superior service beyond that received by the average consumer (Blank 2007). Therefore, expert reviews of an experience may be less diagnostic and thus less relevant for the average consumer. After prior experience, word of mouth (WOM) has been shown to be the most important external source of information to reduce purchase risk (Lutz and Reilly 1974). Though having greater breadth and depth than direct personal experience, traditional WOM is still limited by geographic and social boundaries (Ellison and Fudenberg 1995). Online WOM, on the other hand, has both global presence and enduring content, resulting in an increasingly significant role in the purchase decisions of consumers. One reason that online consumer reviews are so influential is the perception that they reduce risk and provide more credible and trustworthy information (Bickart and Schindler 2001). Researchers have argued that online feedback mechanisms have a larger impact on the firm than traditional WOM because of the unprecedented scale and ability to measure and control customers' reviews and provide personalized feedback (Dellarocas 2003). Online WOM provides significant depth given that aggregate scores are updated on a continuous basis. Consistent with Bayesian hypotheses, research has demonstrated that the number of reviews used in the aggregate score impacts the influence of review scores on performance (Zhu and Zhang 2010).

\section{Hotel Reviews and Online Consumer Behavior}

In the travel space, any discussion of the relationship between guest reviews and hotel classifications needs to be grounded in an understanding of how consumers are researching hotel stays online. Using data from comScore, Anderson (2011) looked at travel-related online behavior that precedes an online booking by tracking the online behavior of a sample of just under 400 consumers for 60 days prior to booking with a major hotel brand. The average number of unique travel sites visited by these consumers during the 60 days prior to booking was 13.60 , 
with consumers visiting each site 2.92 times on average, for a total of 39.90 travel site visits per consumer. In addition, consumers on average performed 8.60 travel-related searches on search engines such as Google, Yahoo, or Bing. Figure 1 illustrates the distribution of travel site visitation before booking a hotel room, and Figure 2 shows the distribution of travel-related searches and travel-related site visits, again prior to making a booking.

The distribution of online behavior indicates that the majority of consumers exhibit online research below the aforementioned averages, with $49 \%$ of consumers visiting 10 or fewer unique travel sites. Nevertheless, a substantial number of consumers do spend considerable time online researching travel (hotel) decisions, with more than $20 \%$ of consumers visiting more than 30 unique sites.

Figure 3 illustrates the distribution of “days before reservation” of visits to TripAdvisor one of the leading sources for online guest reviews. The distribution indicates that research centered on guest reviews (on TripAdvisor at least) is concentrated in the final few days prior to booking, thus supporting the hypothesis that consumers use reviews not to filter hotels, but rather to decide among a smaller choice set already weeded out from prior search and site visitation and falling within desired hotel classification categories. This is consistent with findings from a recent survey of 2,500 consumers where 35\% of respondents use online reviews early on to identify hotels to consider, whereas $28 \%$ use them to narrow down predetermined choices (Carroll 2014).

Much of the innovation in confirming hotel quality has happened from outside the lodging space as online intermediaries look to offer services to entice consumers to research travel needs and make reservations. Online travel sites have spent more than 15 years developing the technology to facilitate online word of mouth. Opaque travel sites have been doing some 
UNWTO 8

form of user review integration into hotel classification for over 10 years. Opaque travel sites like Hotwire.com and Priceline.com mostly operate in the United States. These sites sell rooms not in specific hotels, but in classes of hotels in general areas, e.g., a 4-star hotel in Times Square, New York City.

Figure 4 shows listings from these two travel sites for New York City. The listings jointly show star level and review information, but not names of hotels. Consumers, in return for not knowing the specific name of the hotel until after they have paid for the fully nonrefundable room in advance, receive discounts of $50 \%$ or more. The accuracy of the star information is therefore critical to the success of these sites—for example, if consumers purchase a 4-star hotel but feel it is really a 3-star hotel because of the quality or amenities may not revisit the travel site. Consequently, to decide whether a hotel should be listed as a 3.5-star or 4-star hotel, these sites look at numerous sources, including online guest reviews.

\section{Review Authenticity}

One of the concerns regarding guest reviews is their authenticity. Mayzlin et al. (2014) suggest that hoteliers have incentives to write fictitious positive reviews of their own hotels, and to write negative reviews about competing properties. There are even examples of businesses that have not yet opened but have still received reviews (O’Neill 2012).

Quinby and Rauch (2012) indicate that although most “cheating” appears to be focused on creating fake positive reviews, $98 \%$ of surveyed respondents found TripAdvisor hotel reviews to accurately reflect their actual experience, and that 95\% would recommend TripAdvisor hotel reviews to others. Among 2,739 randomly selected visitors on TripAdvisor, 87\% of the users agree with the statement "guest reviews on TripAdvisor help me feel more confident in my decisions.” Despite travelers' increasing expectations and demands, the study also revealed that 8 
out of 10 users agree that TripAdvisor hotel reviews "help me have a better trip.” Furthermore, the study shows that $53 \%$ of the respondents will not book a hotel that does not have any guest reviews on the site.

Inauthentic reviews can easily be overcome by the utilization of so-called qualified reviews. Most online travel agents (OTAs) only accept reviews from guests who have purchased a room through their site (the OTA sends an email after the stay requesting the consumer feedback on their purchase). Booking.com, the world's largest OTA, has over 30 million of these qualified reviews. Expedia, through its combined pool of reviews from its Expedia.com and Hotels.com brands, has over 20 million. In the case of TripAdvisor, which has over 200 million reviews, the reviewer is not required to have stayed at the hotel. Yet, TripAdvisor is continuously upgrading filters to weed out any reviews it suspects may be fake. Moreover, the sheer magnitude of reviews across all providers is likely to minimize the impact of inauthentic entries.

\section{Online Reviews and Hotel Classification}

Official hotel classifications and online guest reviews potentially serve different yet complementary purposes. One of the issues of integration of guest reviews with classification systems is the degree to which reviews are correlated with star levels. Table 1 presents a summary of user ratings from TripAdvisor for its “top” hotels by star level for eight cities. Panel A of the table shows average TripAdvisor ratings by hotel star level across the eight cities. TripAdvisor ratings consistently increase with increasing star level, but the numbers are quite different by location. The difference in TripAdvisor rating by stars also varies considerably by city. For example, in New York City there is only a 0.35 difference between the average of 2-star and 5-star hotels, whereas this difference is almost two in Sydney. 
UNWTO 10

TripAdvisor, using a proprietary model, ranks hotels by destination. Panel B of Table 1 shows the percentage of each star level within the TripAdvisor "Top 100" hotels. These percentages favor 3- and 4-star hotels, most likely reflecting the "value” component of guest reviews; i.e., lower star hotels may get better reviews than higher star hotels, not because of amenities, but rather because of perceived value for money and exceeding expectations for that star level.

Table 2 provides the average TripAdvisor rating and ranking of hotels according to star level for the top 100 TripAdvisor ranked hotels across 100 major cities worldwide. The data further show that higher star hotels tend to have higher TripAdvisor rankings and better TripAdvisor scores, but that lower star hotels can still be considered top hotels within a market.

In general, the findings indicate that the potential impact of guest reviews on hotel classification increases with decreasing star levels. Consumers appear to react positively, by giving better reviews, to 3- and 4-star hotels that deliver strong value or improved service, whereas for 5-star hotels, it may be more difficult to exceed expectations of consumers.

\section{Survey Stakeholders}

A refinement of hotel classification via the integration of user reviews into traditional classification broadly impacts three sets of stakeholders: consumers, hoteliers, and third-party intermediaries (OTAs). These three sets of stakeholders were surveyed to assess their views on review integration. The survey responses are summarized in the appendix. A consumer survey facilitated by the National Tourism Development Authority of Ireland (NTDAI) resulted in 23,702 responses from Irish travelers. An additional 26,000 responses were received from international travelers for a shorter survey conducted by Tourism Ireland, 575 responses were received from hotel executives, managers, and general managers through Cornell University’s 
UNWTO 11

Center for Hospitality Research, and 27 telephone interviews were conducted with online travel agents.

The NTDAI consumer survey showed that whereas $65 \%$ to $75 \%$ of respondents considered hotel classifications from agencies and/or OTAs to be important or very important in the hotel purchase decision, a larger proportion (93\%) thought the same of recommendations from friends, and $84 \%$ for more anonymous word of mouth via online guest reviews. A Tourism Ireland survey focused on international travelers produced very similar results, with $75 \%$ of respondents indicating classification systems to be important or very important, compared to over $80 \%$ for guest reviews.

As with consumers, hoteliers view official hotel classification as important or very important to their establishment (75\%), but attribute more significance to guest reviews (97\%). The survey showed that hoteliers use consumer reviews predominantly for quality management (72\%) and understanding customer needs (77\%).

The results from OTAs show a different pattern. They consider classification to be one of the most important features of their listings, with guest reviews slightly less important, and the integration of reviews into classification only marginally important. OTAs most likely view integration as less critical owing to their current side-by-side use of reviews and classifications. In essence, they are already offering a mild form of integration.

The views of the three stakeholders on the integration of reviews into classification systems mimic those on the importance of classification systems; about $75 \%$ of both consumers and hotels indicate that the integration of reviews into classification is important or very important, and this reduces to $44 \%$ for OTAs. The lower importance attributed by OTAs is 
understandable because the provision of reviews is one of their competitive advantages, as OTAs heavily advertise their database of qualified reviews.

Despite generally supporting the idea of integration, hoteliers also expressed, via freeform responses from 188 respondents, concerns regarding the methodology for such integration and, in particular, how to deal with inauthentic reviews.

\section{A Framework for Full Integration}

As shown in Tables 1 and 2, higher classified hotels tend to have higher review scores, but they are neither perfectly correlated nor symmetrical across locations. One of the issues with integration is the potential different uses of review and classification information. On the one hand, reviews reflect postpurchase satisfaction and the degree to which expectations have been met; this is the reason why a 2-star hotel may get great reviews compared to, say, a 4-star hotel. On the other hand, classification systems have historically been about an amenity checklist. It is for these differences in purpose that a more granular inclusion of guest review information is proposed.

Table 3 summarizes some of the typical elements evaluated in traditional hotel classification systems in the left column and information sought (by review collectors) in guest reviews in the right column. The table indicates a strong degree of congruency between the information used in classification systems and the feedback sought via consumer reviews.

However, the feedback obtained across review platforms is varied. Table 4 indicates the number of review criteria and scales for the three main review sites as well as the major OTAs. As shown, different regional players and different review platforms focus on differing dimensions in the review data they collect. As such, it is proposed that to get a balanced 
comparison of review data with classification data, review information should be aggregated across the numerous platforms.

Many third-party firms, including popular providers such as Brand Karma, ReviewPro, and TrustYou, carry out this aggregation. In addition, some of these firms break down information into departments across the review criteria categories in Table 3. For example, Table 5 illustrates the aggregated review data supplied by ReviewPro. The table shows ReviewPro’s GRI (Global Review Index ${ }^{\mathrm{TM}}$ ), an overall guest review score that is based on scores by department (food and beverage (F\&B), room, etc.) as well as more subjective, service-related categories (overall cleanliness, service, and value).

Using departmental scores, we can separate the impact of reviews into expectations versus requirements. Departmental scores (from Table 3) could be compared to acceptable regional values based on the distribution of scores for hotels of the designated classification. If a suspect property is below the acceptable range across some departments, it may be classified lower. Similarly if a hotel exceeds acceptable levels (e.g., surpasses the upper level across all departmental scores in Table 5) and also scores highly on nondepartmental elements (value, service, and cleanliness), then it may be classified higher, assuming it meets minimum amenity requirements (and associated departmental scores) of the higher class.

As an illustration, Table 5 displays hotel scores as well as the market average and the top quartile (upper) and bottom quartile (lower) for hotels of the same star classification as the sample hotel. The hotel in question has amenity scores within acceptable ranges, meaning it meets the departmental data requirements for this star category. However, the subjective measures (cleanliness, service, and value) exceed the upper quartile, indicating that it is delivering superior value and service, and may therefore currently be classified too low. 
Depending upon the region and classification system, the subject hotel may then be a candidate for an upgrade in classification.

Table 6 illustrates potential upgrade/downgrade scenarios. Upgrades may, for example, be considered when hotels have superior nondepartmental scores (cleanliness, service, and value) and departmental scores within or above acceptable ranges. Hotels may be downgraded if departmental and nondepartmental scores are below acceptable ranges. Hotel classification would remain unchanged under the majority of settings.

In North America, a classification upgrade may be straightforward, owing to its half-star system; i.e., a superior performing 3-star hotel may be reclassified as a 3.5-star hotel because it has the amenity requirements of that star level. However, in other regions with fewer classification gradations, the subject hotel may not have the amenities required of that higher "star" level. If a hotel is to be upgraded in classification, its departmental review scores will typically need to meet acceptable levels of the new classification, and it is likely that some hotels will choose not to upgrade their amenities. It is up to the certification body to determine if such performance can be "rewarded" in another manner, e.g., a denomination such as "deluxe” or "superior."

It is also probably advantageous to present an aggregate score (GRI from Table 5) in concert with the modified classification. Considering the consumer and hotelier survey responses, it is clear that even more refined classifications will not replace the need for guest reviews, as research consistently shows that consumers value reviews more than classifications. It is expected that consumers may still visit OTAs and review sites to read reviewer comments. In essence, this integration will not replace reviews, but rather use them to improve the classification process. 
UNWTO 15

\section{Financial Impact}

Whether presenting an aggregated guest review score in parallel to a hotel classification or adopting a fully integrated model, costs will be incurred. The financial impact of being officially classified in the first place is difficult to establish. However, a comparison of pricing differences between officially classified versus unclassified hotels reveals considerable differences. Table 7 summarizes data from rates on 2,972 hotels in 18 cities globally. The data indicate that officially classified hotels experienced significant price premiums, attesting to the value consumers assign to official classifications.

Anderson and Lawrence (2014) present the impact of guest reviews on hotel performance and indicate how these impacts are increasing with decreasing star levels. Using online reputation data from ReviewPro and hotel performance data from Smith Travel Research, they show that a $1 \%$ improvement in review score translates into about a $1 \%$ gain in revenue per available room (RevPAR). Table 8 shows these gains by chain scale, with luxury hotels experiencing a $0.49 \%$ gain (percentage gain in RevPAR per percentage gain in review score), and gain increasing to $1.42 \%$ for midscale hotels. The results clearly demonstrate that online reputation, as measured by guest review score, has an increasing impact on hotel performance as the chain scale is decreased. Similarly, using data from 13,341 reservations from seven major U.S. cities made through Travelocity during July 2012, they show that the odds of a consumer booking a hotel increase by 1.142 if their Travelocity Review Score (five-point scale) increases by one point, say from 3.1 to 4.1. As such, if the hotel chooses to increase price (versus market share), a one-point gain translates into about an $11 \%$ gain in price, while maintaining occupancy. 
UNWTO 16

\section{Impact of Integration}

Anderson and Lawrence (2014) show the impact of guest reviews on the performance of hotels of various categories. The degree to which these results would translate to hotels that are classified using an integrated model of guest reviews and traditional classification is difficult to establish. However, the integration of reviews into classification should help reduce consumer uncertainty regarding individual hotels, thereby giving hotels with integrated classification pricing power over those without. This would also mean that markets with integrated classification should have pricing power over those without. The results from Tables 1 and 5 indicate that impacts from integration may be more pronounced for midscale and upper midscale hotels (3 to 4 stars). This in turn raises the question of whether overall average daily rates would increase if entire regions adopted an integration strategy. To some degree, the travel market is inelastic; i.e., consumers are probably not going to travel more because the quality of hotel classification systems improves. Yet, they may be willing to pay more for a product that better meets expectations.

\section{Summary}

Today’s consumers seek many sources of information during their purchase processespecially for services and experience goods like hotel stays. Recent years have seen an explosion in user-generated reviews, with consumers increasingly expressing opinions on recent purchases as well as seeking opinions of others prior to their purchases. During the early growth phase of guest reviews, hotels and consumers had expressed concerns with the authenticity of reviews; but with today’s over 300 million reviews across numerous travel-related sites, the wisdom of the crowd dwarfs potentially fraudulent reviews. 
The ease of access to information requires an updated approach to how we look at hotel classification, with $75 \%$ of surveyed consumers and hotels indicating that the integration of reviews into classification is potentially important. At the same time, consumers appear to use guest reviews and hotel classifications in different manners-classification systems help filter hotels, whereas guest reviews provide a means to help select from a smaller set of acceptable options. These similar yet distinct uses indicate a continued need for both hotel classification and guest reviews. Hence, we propose a modification to existing classifications systems that includes guest review data. This new classification system can be used in concert with existing guest review sites and data—with consumers continuing to use both as seen fit.

Prior research clearly shows a link between hotel performance and guest review scores. Whether the link between hotel performance and guest review scores directly translates to an integrated classification model is unknown, but some gain is anticipated, as consumer confidence in hotel classification should increase purchase intention.

We present a framework for the integration of user reviews into hotel classification using review scores by hotel department (house keeping, front deck, etc.) and subjective, nondepartmental data (quality, service, and value) to ensure consistent use of review information within a traditional hotel classification framework. Moreover, we propose the use of aggregated review scores across numerous review platforms to support review authenticity.

At present, the proposed framework is untested. A next step would be to test the framework within a given region, e.g., incorporating reviews into the classification of hotels in some but not all cities. Testable metrics would be the number of hotels reclassified (both up and down) as a result of integration and then a comparison of hotel performance (ADR, RevPAR and Occupancy) both at the hotel level as well as by market or city. 
UNWTO 18

\section{References}

Anderson CK (2011) Search, OTAs, and online booking: An expanded analysis of the billboard effect. Cornell Hospitality Rep. 11(8):6-10.

Anderson CK, Lawrence B (2014) The influence of online reputation and product heterogeneity on service firm financial performance. Service Sci. 6(4):217-228.

Bickart B, Schindler RM (2001) Internet forums as influential sources of consumer information. J. Interactive Marketing 15(3):31-40.

Blank G (2007) Critics, Ratings, and Society: The Sociology of Reviews (Rowman \& Littlefield, Lanham, MD).

Callan RJ (1990) Hotel award scheme as a measurement of service quality: An assessment by travel-industry journalists as surrogate consumers. Internat. J. Hospitality Management 9(10):45-48.

Callan RJ (1995) Hotel classification and grading schemes: A paradigm of utilization and user characteristics. Internat. J. Hospitality Management 14(3):271-84.

Carroll P (2014) Digging deeper into hotel reviews: Exactly how and why travelers use them. eHotelier (July 2), http://ehotelier.com/news/2014/07/02/digging-deeper-into-hotelreviews-exactly-how-and-why-travelers-use-them/.

Dellarocas C (2003) The digitization of word of mouth: Promise and challenges of online feedback mechanisms. Management Sci. 49(10):1407-1424.

Eliashberg J, Shugan SM (1997) Film critics: Influencers or predictors? J. Marketing 61(2):6878.

Ellison G, Fudenberg D (1995) Word-of-mouth communication and social learning. Quart. J. Econom. 110(1):93-125. 
Fernandez MCL, Bedia AMS (2004) Is the hotel classification system a good indicator of hotel quality? An application in Spain. Tourism Management 25(6):771-775.

Lutz RJ, Reilly PJ (1974) An exploration of the effects of perceived social and performance risk on consumer information acquisition. Adv.Consumer Res. 1(1):393-405.

Mayzlin D, Dover Y, Chevalier JJ (2014) Promotional reviews: An empirical investigation of online review manipulation. Amer. Econom. Rev. 104(8):2421-2455.

O’Connor P (2010) Managing a hotel’s image on TripAdvisor. J. Hospitality Marketing Management 19(7):754-772.

O’Neill S (2012) TripAdvisor responds to provocative study of bogus online reviews. Tnooz Reports (August 23), https://www.tnooz.com/article/tripadvisor-responds-to-provocativestudy-of-bogus-online-reviews/.

Parasuraman A, Berry LL, Zeithaml VA (1985) A conceptual model of service quality and it implications for future research. J. Marketing 49(4):41-50.

Quinby D, Rauch M (2012) Social Media in Travel 2012: Social Networks and Traveler Reviews (PhoCusWright, New York).

Reinstein DA, Snyder CM (2005) The influence of expert reviews on consumer demand for experience goods: A case study of movie critics. J. Indust. Econom. 53(1):27-51.

Shapiro C (1982) Consumer information, product quality, and seller reputation. Bell J. Econom. 13(1):20-35.

Su CS, Sun LH (2007) Taiwan’s hotel rating system a service quality perspective. Cornell Hospitality Quart. 48(4):392-401.

United Nations World Tourism Organization (UNTWO) (2015) Tourism highlights: 2015 edition. Report, United Nations World Tourism Organization, Madrid. 
Zhu F, Zhang XM (2010) Impact of online consumer reviews on sales: The moderating role of product and consumer characteristics. J. Marketing 74(2):133-148. 
UNWTO 21

Table 1. Average TripAdvisor Ratings

\begin{tabular}{|c|c|c|c|c|c|c|c|c|}
\hline Star level & New York & Chicago & Los Angeles & Melbourne & Sydney & Copenhagen & Stockholm & Berlin \\
\hline \multicolumn{9}{|c|}{ Panel A: Average ratings by stars } \\
\hline 2 & 4.13 & 3.56 & 3.91 & 3.50 & 2.43 & 3.18 & 3.44 & 3.67 \\
\hline 3 & 4.24 & 4.03 & 3.84 & 3.22 & 3.30 & 3.51 & 3.70 & 3.77 \\
\hline 4 & 4.29 & 4.15 & 4.01 & 3.83 & 3.69 & 3.60 & 3.94 & 4.09 \\
\hline 5 & 4.48 & 4.63 & 4.41 & 4.35 & 4.34 & 4.08 & 4.10 & 4.50 \\
\hline \multicolumn{9}{|c|}{ Panel B: Top TripAdvisor hotels by stars (\%) } \\
\hline 2 & 2.0 & 7.0 & 13.3 & 0.8 & 6.0 & 15.1 & 6.6 & 11.3 \\
\hline 3 & 35.3 & 50.4 & 48.3 & 19.2 & 23.9 & 45.2 & 37.7 & 39.8 \\
\hline 4 & 47.3 & 35.7 & 29.2 & 64.6 & 48.7 & 33.3 & 51.6 & 40.4 \\
\hline 5 & 15.4 & 7.0 & 9.2 & 15.4 & 21.4 & 6.5 & 4.1 & 8.5 \\
\hline
\end{tabular}

Table 2. Average TripAdvisor Ratings-100 Global Markets

\begin{tabular}{lcc}
\hline Star & Average ranking & Average review score \\
\hline 1 & 56.1 & 3.95 \\
1.5 & 57.5 & 3.30 \\
2 & 58.0 & 3.75 \\
2.5 & 53.7 & 3.97 \\
3 & 53.7 & 4.01 \\
3.5 & 51.1 & 4.10 \\
4 & 46.5 & 4.20 \\
4.5 & 38.9 & 4.31 \\
5 & 30.3 & 4.43 \\
\hline
\end{tabular}


Table 3. Hotel Classification and Guest Review Categories

\begin{tabular}{ll}
\hline Criteria categories & \\
\hline Hotel classification systems & \multicolumn{1}{c}{ Guest reviews } \\
\hline Room & Room comfort/standard \\
Service & Service \\
Food and beverage & Food and dining \\
Access & Location \\
Front desk services & Staff performance \\
Communication & Value for money \\
$\quad$ internal and external marketing) & \\
Bathroom & Cleanliness \\
Temperature control & \\
\hline
\end{tabular}

Table 4. Number of Guest Review Categories by OTA/Review Site

\begin{tabular}{|c|c|c|c|}
\hline & Main location & $\begin{array}{c}\text { Number of } \\
\text { criteria }\end{array}$ & Scale \\
\hline \multicolumn{4}{|c|}{ Guest review sites } \\
\hline HolidayCheck & Europe/Germany & 6 & $1-6$ \\
\hline MyTravelGuide & United States & 3 & $1-10$ \\
\hline TripAdvisor & Worldwide & 8 & $1-5$ \\
\hline \multicolumn{4}{|c|}{ OTAs } \\
\hline Agoda & Asia & 6 & $1-10$ \\
\hline Atrapalo & Spanish site/worldwide & 8 & $1-10$ \\
\hline Booking & Worldwide & 6 & $1-10$ \\
\hline Expedia & Worldwide & 4 & $1-5$ \\
\hline Hotels & Worldwide & 5 & $1-5$ \\
\hline HotelTravel & India and expanding & 6 & $1-5$ \\
\hline HRS & Worldwide & 14 & $1-10$ \\
\hline Orbitz & Worldwide & 6 & $1-5$ \\
\hline Priceline & United States & 4 & $1-10$ \\
\hline
\end{tabular}


UNWTO 23

Table 5. Sample of ReviewPro's Aggregated Departmental Scores (\%)

\begin{tabular}{lcccccccccc}
\hline Market & GRI & Room & Decor & Entertain & F\&B & Location & Reception & Clean & Value & Service \\
\hline Average & 77.4 & 81.2 & 79.7 & 79.5 & 70.0 & 80.2 & 81.1 & 76.1 & 74.7 & 75.7 \\
Upper & 83.3 & 85.1 & 87.6 & 83.8 & 73.9 & 82.9 & 82.7 & 83.4 & 80.7 & 80.4 \\
Lower & 71.4 & 77.6 & 71.5 & 75.2 & 66.1 & 77.1 & 79.3 & 69.6 & 68.3 & 70.0 \\
Hotel & 81.0 & 80.2 & 77.5 & 81.7 & 83.0 & 83.1 & 80.2 & 83.5 & 81.7 & 85.1 \\
\hline
\end{tabular}

Table 6. Potential Upgrade and Downgrade Scenarios

\begin{tabular}{lccc}
\hline Departmental scores & \multicolumn{2}{c}{ Nondepartmental scores } \\
$\begin{array}{l}\text { Above upper quartile }(+) \\
\text { Within range (=) }\end{array}$ & $\begin{array}{c}\text { Above upper quartile }(+) \\
\text { Within range }(=) \\
\text { Below lower quartile }(-)\end{array}$ & $\begin{array}{c}\text { Result } \\
\text { Below lower quartile }(-)\end{array}$ \\
\hline$=$ & + & $\begin{array}{c}\text { Candidate for upgrade }(+) \\
\text { No change }(=) \\
\text { Candidate for downgrade }(-)\end{array}$ \\
$=$ & - & $=$ \\
$=$ & $=$ & $=$ \\
+ & + & $=$ \\
+ & - & + \\
+ & + & $=$ \\
- & $=$ & $=$ \\
- & - & - \\
- & & $=$ \\
\hline
\end{tabular}

Table 7. Hotel Price Differences Between Classified and Unclassified Hotels

\begin{tabular}{lccc}
\hline & \multicolumn{3}{c}{ Price } \\
\cline { 2 - 4 } Classification & Classified & Unclassified & \% difference \\
\hline $5 \star$ & EUR 255 & EUR 187 & 36 \\
$4 \star$ & EUR 145 & EUR 118 & 23 \\
$3 \star$ & EUR 121 & EUR 83 & 46 \\
$2 \star$ & EUR 93 & EUR 72 & 29 \\
\hline
\end{tabular}


Table 8. Impact of Guest Reviews on Hotel Performance-Percentage Changes in Average Daily Rate (ADR), Occupancy, and Revenue per Available Room Given a 1\% Change in Review Score

\begin{tabular}{lccc}
\hline & $\begin{array}{c}\text { Pricing power } \\
\text { (ADR) }\end{array}$ & $\begin{array}{c}\text { Demand } \\
\text { (Occupancy) }\end{array}$ & $\begin{array}{c}\text { Performance } \\
\text { (RevPAR) }\end{array}$ \\
\hline All & 0.80 & 0.20 & 0.96 \\
Luxury & 0.44 & 0.09 & 0.49 \\
Upper upscale & 0.57 & 0.30 & 0.74 \\
Upscale & 0.67 & 0.19 & 0.83 \\
Upper midscale & 0.74 & 0.42 & 1.13 \\
Midscale & 0.89 & 0.54 & 1.42 \\
\hline
\end{tabular}




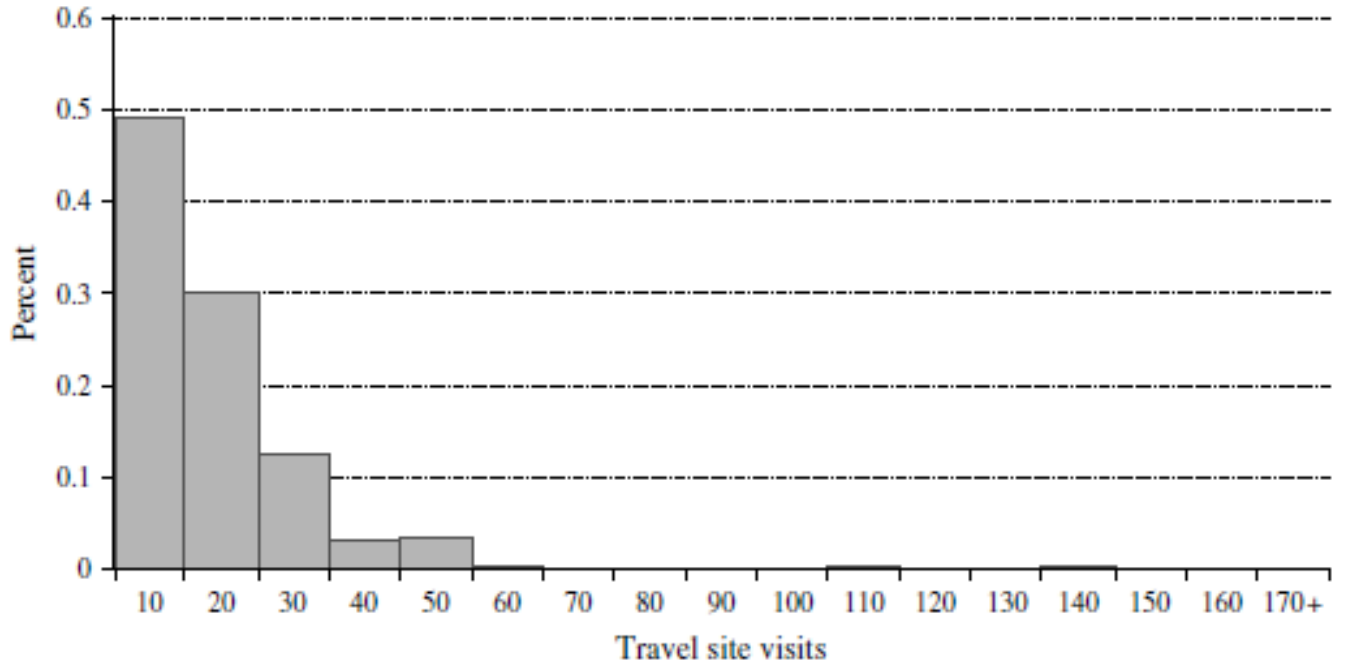

Figure 1. Distribution of Travel Site Visits 
UNWTO 26

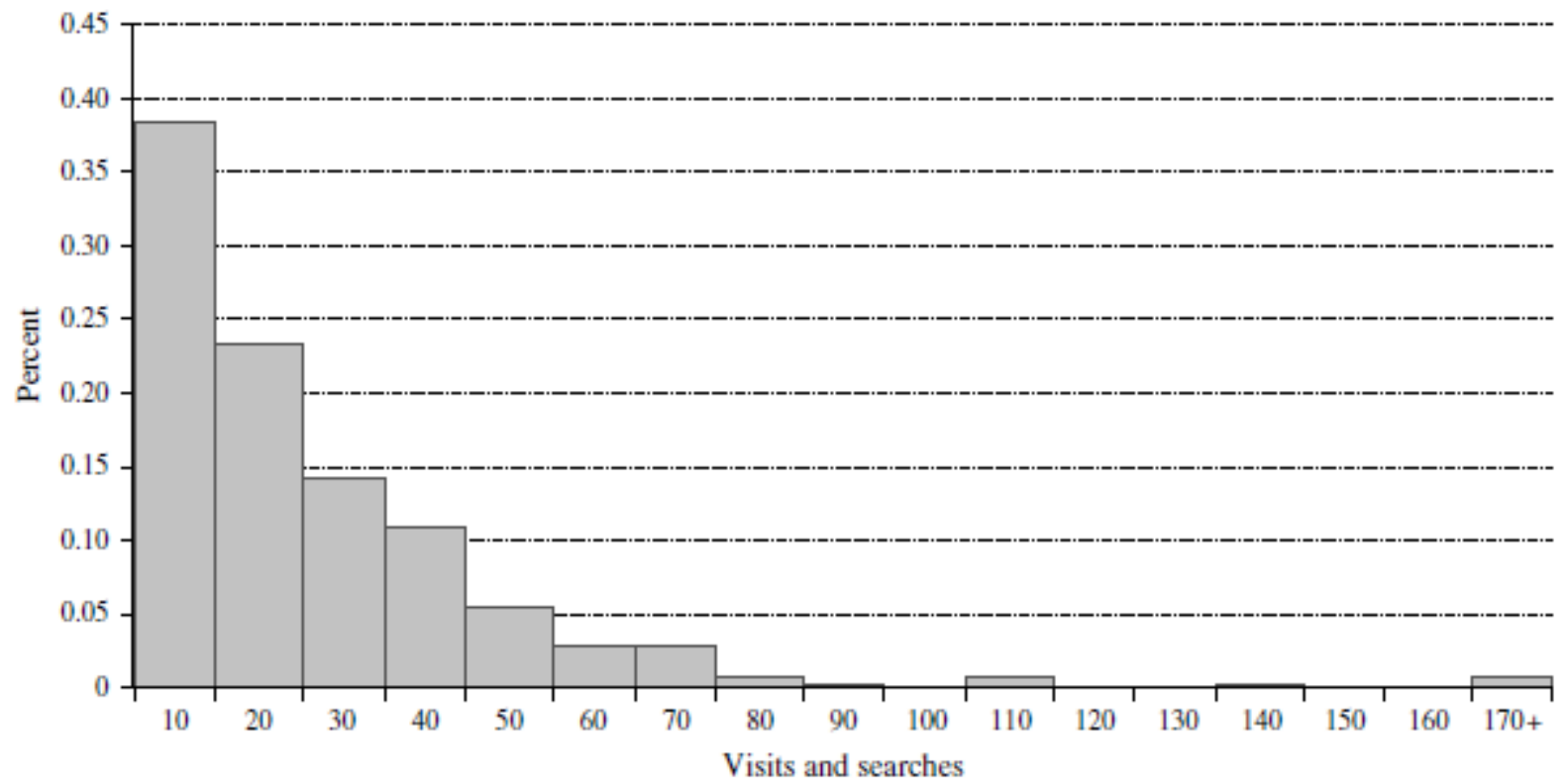

Figure 2. Distribution of Travel Site Visits and Searches 


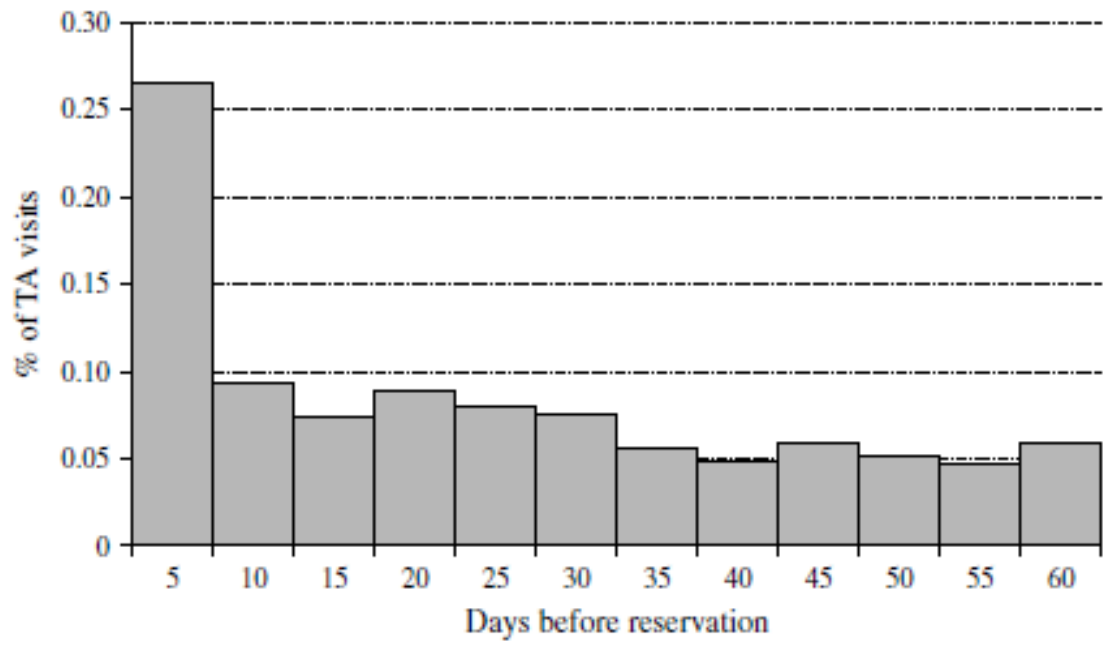

Figure 3. Distribution of Days Before Booking of TripAdvisor Visits 
UNWTO 28

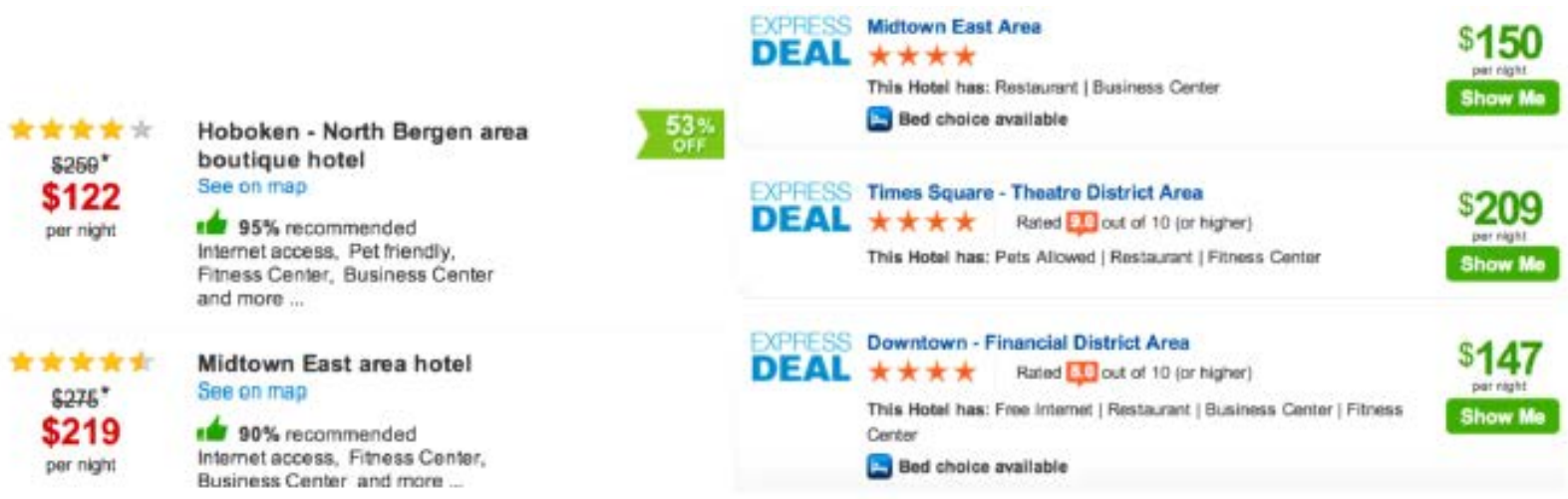

Figure 4. Opaque Hotel Listings in New York

Source. Left, Hotwire.com (accessed May 6, 2014). Right, Priceline.com (accessed May 6, 2014). 


\section{Appendix}

\section{Summary Statistics}

The following summarizes three data sources: telephone interviews with online travel agents, surveys of consumers facilitated by the NTDAI and Tourism Ireland, and a survey of hoteliers though Cornell University’s Center for Hospitality Research.

\section{Consumers}

Irish Consumers. Tables A.1-A.3 summarize 23,702 responses received from the NTDAI; $55.90 \%$ of respondents were male and $44.10 \%$ were female, with an age distribution as summarized in Figure A.1.

Figure A.1. NTDAI Survey Respondents by Age

What is your age category? (Don't answer this if you do not wish to)

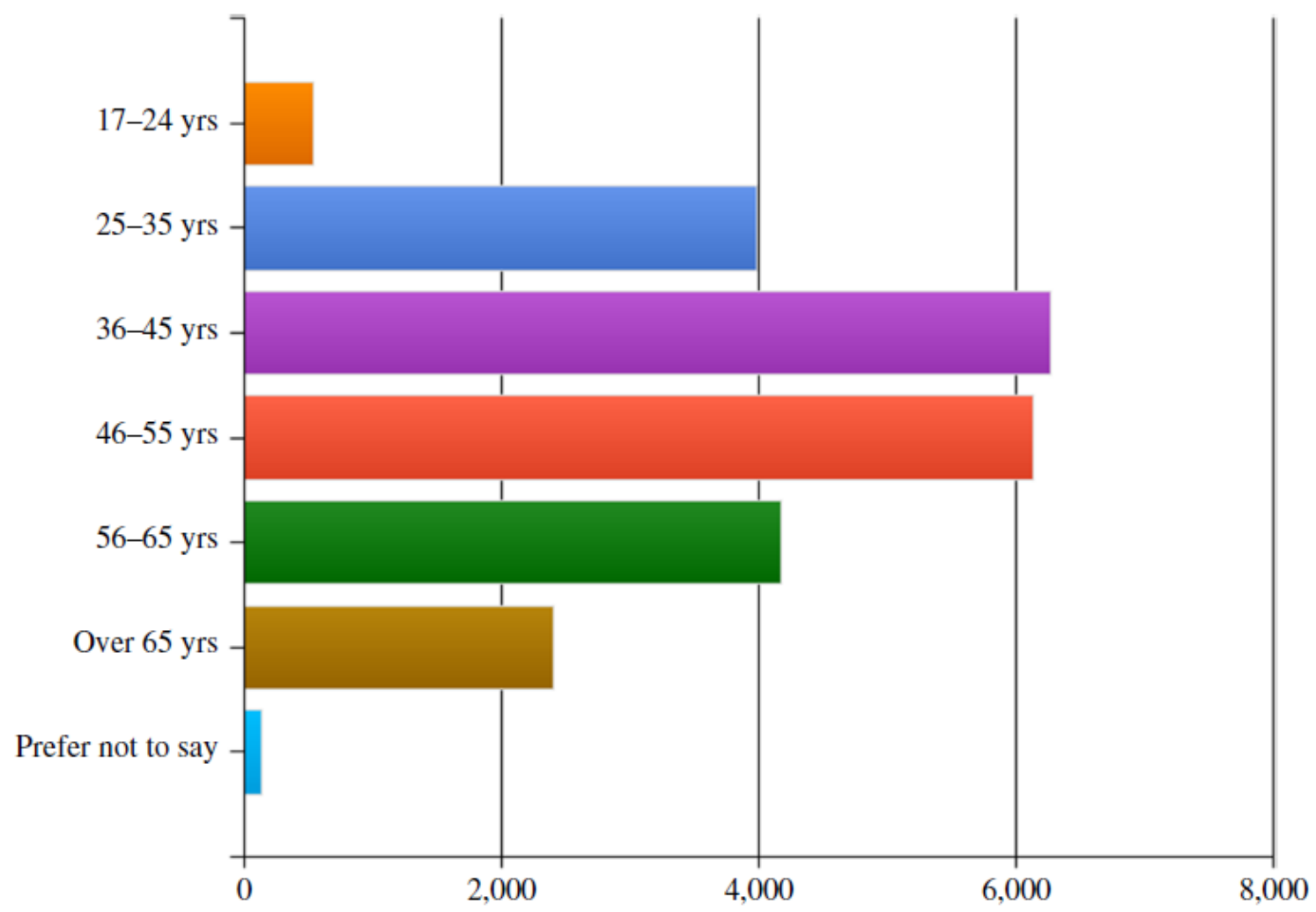


Table A. 1. When You are Choosing a Hotel to Stay In, How Would You Rate the Relative Importance of Information That You Receive From the Following Sources? (Answers in \%)

\begin{tabular}{lccccc}
\hline & $\begin{array}{c}\text { Very } \\
\text { important }\end{array}$ & $\begin{array}{c}\text { Somewhat } \\
\text { important }\end{array}$ & Neutral & $\begin{array}{c}\text { Not very } \\
\text { important }\end{array}$ & $\begin{array}{r}\text { Not at all } \\
\text { important }\end{array}$ \\
\hline $\begin{array}{l}\text { An official rating classification (e.g., from } \\
\quad \text { Failte Ireland for Irish hotels) }\end{array}$ & 25.1 & 40.8 & 18.2 & 9.7 & 6.2 \\
$\begin{array}{c}\text { A consumer rating system (e.g., AA, } \\
\text { "Blue book," etc.) }\end{array}$ & 21.1 & 43.5 & 21.0 & 8.5 & 5.9 \\
$\begin{array}{l}\text { A rating from a hotel booking site (e.g., } \\
\quad \text { TripAdvsior, Trivago, etc.) }\end{array}$ & 30.0 & 44.5 & 15.2 & 6.5 & 3.8 \\
$\begin{array}{l}\text { Recommendation from friends/word of } \\
\text { mouth }\end{array}$ & 62.7 & 30.3 & 4.7 & 1.2 & 1.1 \\
$\begin{array}{l}\text { Information from Facebook, Twitter, or } \\
\text { social media }\end{array}$ & 6.1 & 22.5 & 32.0 & 17.5 & 21.9 \\
$\begin{array}{l}\text { Other (please detail in the comments box } \\
\text { below) }\end{array}$ & 7.1 & 6.3 & 39.4 & 6.0 & 41.2 \\
\hline
\end{tabular}

Table A.2. Please Mark the Appropriate Response To the Questions Below on the Scale Provided (Answers in \%)

\begin{tabular}{lccccc}
\hline & $\begin{array}{c}\text { Very } \\
\text { important }\end{array}$ & $\begin{array}{c}\text { Somewhat } \\
\text { important }\end{array}$ & Neutral & $\begin{array}{c}\text { Not very } \\
\text { important }\end{array}$ & $\begin{array}{r}\text { Not at all } \\
\text { important }\end{array}$ \\
\hline $\begin{array}{l}\text { How important is it to you that a hotel should } \\
\text { have an official classification? }\end{array}$ & 45.3 & 38.7 & 9.7 & 4.3 & 2.0 \\
$\begin{array}{l}\text { When you are choosing a hotel, how important } \\
\text { would you consider guest reviews of that } \\
\text { hotel to be? }\end{array}$ & 38.1 & 46.0 & 10.1 & 4.0 & \\
$\begin{array}{l}\text { When you are choosing a hotel, how important } \\
\text { is it for you that a guest review website } \\
\text { clearly indicates the official classification/star } \\
\text { rating of the hotel reviewed? }\end{array}$ & 32.4 & 40.7 & 18.2 & 5.7 & 3.1
\end{tabular}


Table A.3.How Valuable Would It Be For You if Guest Reviews Were an Integrated Part of Official Classification/Star Rating? (Answers in \%)

Very valuable

Somewhat valuable

Neutral

Not very valuable

Not at all valuable
28.6

45.0

17.8

5.8

2.9

\section{International Consumers.}

As a follow-up, Tourism Ireland sampled a pool of international travelers in an effort to confirm the robustness of the NTDAI sample. The survey was shorter, with the results of the 26,000 respondents summarized in Table A.4. Table entries are shown as the percentages of respondents indicating the importance of reviews and hotel classifications across the five countries of origin of the respondents.

This “international” survey, conducted by the United Nations World Tourism Organization and QualityMark Norway, comprised responses from 279 respondents from over 70 countries and was conducted directly by the report team using the Internet as shown in Table A.5.

\section{Hoteliers.}

Tables A.6-A.9 summarize 575 responses obtained from a global database of hotel industry professionals (executives, managers, supervisors, and general managers) via Cornell's Center for Hospitality Research.

\section{OTAs.}

A telephone survey of 27 stakeholders was conducted. It is evident from the survey that they not only consider official classifications important to their websites, but also consider it 
important that they are displayed with guest reviews. Just over half of them favor guest reviews being an integral part of official classifications/star gradings. A quarter of them think it is not important.

1. How important is it to your website that the hotel has an official classification/star rating?

- Most important 67\%

- Important $19 \%$

2. How important is it to your website that guest review sites clearly indicate the official star rating of the hotel property?

- Most important 52\%

- Important $26 \%$

3. How valuable would it be to make guest reviews an integral part of hotel official star rating?

- Most important $44 \%$

- Important $15 \%$

- Not important $22 \%$ 
UNWTO 33

Table A.4. Importance of Guest Reviews by Country of Respondent

\begin{tabular}{|c|c|c|c|c|c|}
\hline & \multicolumn{5}{|c|}{$\%$ of respondents } \\
\hline & Great Britain & U.S. & Germany & France & Australia \\
\hline \multicolumn{6}{|c|}{ Guest reviews to hotel booking decision } \\
\hline Very important & 61 & 69 & 51 & 39 & 69 \\
\hline Important & 21 & 17 & 21 & 31 & 23 \\
\hline \multicolumn{6}{|c|}{ Guest review site clearly indicates official classification/star rating } \\
\hline Very important & 60 & 61 & 49 & 40 & 60 \\
\hline Important & 21 & 20 & 21 & 25 & 23 \\
\hline \multicolumn{6}{|c|}{ Value of integrating guest reviews as part of official classification/star rating } \\
\hline Very valuable & 59 & 67 & 44 & 42 & 60 \\
\hline Valuable & 21 & 17 & 20 & 24 & 22 \\
\hline \multicolumn{6}{|c|}{ Importance of hotel official classification/star rating when selecting hotels } \\
\hline Very important/valuable & 55 & 64 & 51 & 45 & 67 \\
\hline Important/valuable & 20 & 22 & 21 & 24 & 21 \\
\hline
\end{tabular}

Table A.5. International Survey: Importance of Guest Reviews (\% of Respondents)

\begin{tabular}{|c|c|}
\hline & Percentage \\
\hline \multicolumn{2}{|c|}{ Guest reviews to hotel booking decision } \\
\hline Very important & 83 \\
\hline Important & 12 \\
\hline \multicolumn{2}{|c|}{$\begin{array}{l}\text { Guest review site clearly indicates official } \\
\text { classification/star rating }\end{array}$} \\
\hline Very important & 65 \\
\hline Important & 22 \\
\hline \multicolumn{2}{|c|}{$\begin{array}{l}\text { Value of integrating guest reviews as part of official } \\
\text { classification/star rating }\end{array}$} \\
\hline Very valuable & 65 \\
\hline Valuable & 22 \\
\hline \multicolumn{2}{|c|}{$\begin{array}{l}\text { Importance of hotel official classification' } \\
\text { star rating when selecting hotels }\end{array}$} \\
\hline Very important/valuable & 65 \\
\hline Important/valuable & 22 \\
\hline
\end{tabular}

Table A.6. Importance of Hotel Reviews and Classification to Hotel Owners, Operators, and Managers

\begin{tabular}{|c|c|c|c|c|c|}
\hline Question & $\begin{array}{l}\text { Extremely } \\
\text { important }\end{array}$ & $\begin{array}{c}\text { Very } \\
\text { important }\end{array}$ & Neutral & $\begin{array}{l}\text { Very } \\
\text { unimportant }\end{array}$ & $\begin{array}{l}\text { Not at all } \\
\text { important }\end{array}$ \\
\hline $\begin{array}{l}\text { How important are guest reviews to your } \\
\text { firm? }\end{array}$ & 69 & 28 & 2 & 1 & 1 \\
\hline $\begin{array}{l}\text { How important is official hotel } \\
\text { classification to your firm? }\end{array}$ & 33 & 42 & 21 & 3 & 2 \\
\hline $\begin{array}{l}\text { How valuablefimportant do you think it } \\
\text { would be to incorporate online reviews } \\
\text { in classification systems }\end{array}$ & 26 & 46 & 16 & 5 & 6 \\
\hline
\end{tabular}


Table A.7. What Are The Key Elements/Uses of Online Reviews Within Your Firm? (Select Up to Five)

\begin{tabular}{rlr}
\hline 1 & Quality management & 72 \\
2 & Staff training & 50 \\
3 & Interaction/communication with guests & 47 \\
4 & Marketing tool & 35 \\
5 & Understanding customer needs & 77 \\
6 & Improving keyword content for & 6 \\
& $\quad$ search engine marketing & 15 \\
7 & Increase ADR & 18 \\
8 & Increase occupancy & 11 \\
9 & Justification of rate & 72 \\
10 & Improve product or service & 40 \\
11 & Create customer loyalty & 41 \\
12 & Customer engagement & 17 \\
13 & Let customer do marketing & 11 \\
14 & Increase review volume & 25 \\
15 & Benchmarking & 2 \\
16 & No perceived added value & 2 \\
17 & More an issue of being present
\end{tabular}

Table A.8. To What Extent Do You Encourage Guests to Write Online Reviews?

\begin{tabular}{ll}
\hline Periodically (campaigns) & 21 \\
Always & 68 \\
Never & 11 \\
\hline
\end{tabular}

Table A.9. How Are Reviews Followed Up on Major Review Sites (Choose All that Apply)

$\begin{array}{ll}\text { Reviews are used just for benchmarking } & 17\end{array}$

All reviews are replied to in due time 61

Only positive reviews are replied to 2

Only negative reviews are replied to 13

Reviews are discussed internally and $\quad 78$

appropriate actions taken

No actions taken 2 